\title{
A INTERDISCIPLINARIDADE ENTRE O ENSINO DE FILOSOFIA E AS ARTES NA RESIDÊNCIA PEDAGÓGICA
}

The interdisciplinarity between the Teaching of Philosophy and the arts in the pedagogical residency

La interdisciplinariedad entre la enseñanza de la filosofía y las artes en la residencia pedagógica

Paulo Sérgio Gomes Soares*1, Ailla Ligia e Santos Quirino, Ana Kalline e Santos, Fernando Lourenço Barros, Wedison Monteiro Dourado, Adriano Luiz Maropo.

${ }^{1}$ Curso de Filosofia. Universidade Federal do Tocantins, Tocantins, Brasil

${ }^{*}$ Correspondência: Coordenação de Filosofia. Av. NS15, Quadra 109N, UFT, Sala 16, CEP 77001-090. Palmas-

Tocantins.e-mail psoares@uft.edu.br

Artigo recebido em 23/03/2020 aprovado em 09/04/2020 publicado em 20/04/2020.

\section{INTRODUÇÃO}

No ano de 2019, a equipe de residentes iniciou a etapa de imersão na Escola Estadual Santa Fé, localizada no bairro Taquaralto, município de Palmas - TO, após receberem um curso de formação de residentes e passarem por um período de ambientação na escola de agosto a dezembro de 2018. O objetivo desse artigo é compartilhar a experiência obtida na Semana Filosófica organizada pelos residentes junto aos estudantes do Ensino Médio, bem como os resultados alcançados, em termos de formação de professores, considerando o projeto "Metodologias alternativas para o Ensino de Filosofia", que balizou as intervenções, com a finalidade de ensinar a filosofar ${ }^{1}$ a partir de diferentes expressões artísticas, ou expor o pensamento filosófico para além do textual, usando a poesia, a música, a dança, o teatro, a confecção de material didático (como cartazes, maquetes $\mathrm{e}$ protótipos), a produção de material audiovisual, dentre outros. Os residentes participaram de diversas atividades e projetos da/na escola, além das atividades de planejamento e regência com três turmas, na $1^{\circ}, 2^{\circ}$ e $3^{\circ}$ séries do Ensino Médio, cada turma com 35 a 40 estudantes, sob a supervisão da preceptora. A Semana Filosófica foi uma experiência tida como bemsucedida pelos residentes, pois foi a culminância dos estudos filosóficos de um bimestre em que os estudantes expuseram de maneira interdisciplinar o entendimento - leitura e interpretação - do pensamento de diferentes filósofos, valorizando a criatividade e a sensibilidade, bem como a participação dos grupos, necessária no ato de avaliar.

\section{METODOLOGIAS E MATERIAIS}

No processo de formação de professores para o Ensino de Filosofia foi proposto que os residentes exercitassem a prática docente de acordo com as suas próprias habilidades e competências, mas adequando as metodologias para atender às demandas sociais trazidas pelos estudantes. A ideia foi ensinar a filosofar aproveitando as suas próprias experiências pessoais na prática docente criativa para desenvolver atividades em sala de aula, perfazendo uma metodologia que valorizasse a autonomia do residente, ao mesmo tempo em que procurava responder aos problemas apontados no processo de ensino e aprendizagem. A preceptora

${ }^{1}$ Referência ao "mote kantiano de que "não se ensina Filosofia, ensina-se a filosofar"” (BRASIL, 1999, p. 334). 
relatou a dificuldade de leitura, interpretação e escrita de textos filosóficos pelos estudantes, que se convertiam em sérios problemas para o Ensino de Filosofia que precisavam de respostas.

Os residentes deveriam criar alternativas para ensinar os estudantes a filosofar que fossem atraentes e que modificassem essa realidade, bem como a percepção em relação à disciplina. Para tanto, utilizaram a metodologia da sala de aula invertida.

Basicamente, o conceito de sala de aula invertida é o seguinte: o que tradicionalmente é feito em sala de aula, agora é executado em casa, e o que tradicionalmente é feito como trabalho de casa, agora é realizado em sala de aula" (BERGMANN; SAMS, 2016, p. 11).

Os estudantes foram divididos em grupos de três a quatro componentes por escolha própria ou aptidão artística, sendo orientados a pesquisar e estudar em casa e desenvolver as atividades práticas na sala de aula, organizando-se para apresentar os trabalhos artísticos e expor a interpretação. Para tanto, foi fundamental respeitar e estimular a participação por meio do diálogo no transcorrer das aulas, dando voz como condição de politicidade (FREIRE, 1987).

As temáticas do bimestre foram os seguintes: “Os Pré-Socráticos" e o "Mito da Caverna", de Platão. A maioria dos trabalhos foram expostos em forma de desenhos em cartazes, quadrinhos e teatro. Pelo menos uma das notas do bimestre foi lançada na caderneta com base nessas atividades. Conforme os residentes, muitos estudantes com dificuldades de aprendizagem - sobretudo de produção textual - participaram das atividades e conseguiram melhorar o seu desempenho, apresentando a compreensão do pensamento filosófico de forma autônoma ao dispor livremente dos recursos que dispunha para se expressar.

$\mathrm{O}$ ato de avaliar em Filosofia está envolto em contradições, já que o Ensino de Filosofia tem como fulcro gerar a emancipação do pensamento, enquanto o sistema escolar reprodutivista prima pela manutenção da ordem vigente, classificando os estudantes com notas e diferindo os bem-sucedidos dos que fracassaram. A avaliação é algo institucional que exige a submissão de professores e estudantes ao totalitarismo da ordem vigente. A proposta de ensinar a filosofar de maneira alternativa e valorizar as diferentes formas de expressar o pensamento procurou romper com esse ciclo de reprodução, tendo em vista que o Ensino de Filosofia não se harmoniza com as exigências institucionais de avaliação. Notadamente, a avaliação acaba sendo algo puramente institucional (MURCHO, 2014).

\section{RESULTADOS E DISCUSSÃO}

O Parâmetros Curriculares Nacionais (PCNs, 1999) explicitam que a Filosofia no Ensino Médio tem por função restituir o sentido de totalidade ao conhecimento fragmentado pela separação do conhecimento em áreas estanques que parecem não conversar entre si em função da superespecialização.

É necessário, mais do que nunca, levar o aluno a ampliar seu campo de visão até a inteira latitude do real, no sentido de apreendê-lo, não como um amontoado caótico de coisas independentes e que apenas se sucedem desordenadamente, mas, sim, como um conjunto de relações entre todos os seus elementos, como uma trama que supõe a costura e o entrelaçamento dos fios: é preciso tomar o real como uma totalidade inter-relacionada (PCNs, 1999, p. 340).

Diante do exposto, tanto os residentes quanto os estudantes foram convidados a exercitar a interdisciplinaridade, vendo nas artes uma possibilidade de pensar a Filosofia, expressando-a livremente. O conteúdo programático foi trabalhado normalmente, bem como o livro didático se manteve como a principal referência para os estudos filosóficos, embora em vários momentos foi estimulado o trabalho de leitura e pesquisa em casa a partir de outras fontes, com a finalidade de resguardar o tempo na escola para desenvolver atividades práticas - seja para apresentações artísticas (poesia, dança, teatro, música, Revista Desafios - v. 7, n. Supl. RP-UFT, 2020 
etc.), seja para a confecção de material didático em forma de cartazes, desenhos, panfletos, etc.

Os textos filosóficos são fundamentais para trabalhar os problemas filosóficos ao longo da História da Filosofia, mas a proposta foi ir além e buscar maneiras de tornar as aulas de Filosofia interessantes e participativas para os estudantes, permitindo que expusessem suas interpretações textuais da forma como se sentissem melhor. Sabidamente, os estudantes do Ensino Médio podem apresentar dificuldades para escrever, mas podem se tornar participativos nas atividades práticas que valorizam o seu jeito de pensar. Foi a forma encontrada para fazer com que eles estudassem os textos e se interessassem por expor algum entendimento sobre as ideias. Todas as atividades foram registradas em fotos e vídeos pelos residentes e expostos nos murais da escola.

\section{CONCLUSÃO}

Os resultados das intervenções durante a Semana Filosófica foram muito satisfatórios, já que os residentes procuraram responder a três dificuldades constatadas no processo de ensino e aprendizagem no Ensino de Filosofia - os estudantes têm dificuldade em ler, interpretar e escrever textos filosóficos. Trabalharam com vistas na interdisciplinaridade e exerceram a docência de forma autônoma e responsável, ressaltando a importância do Programa Residência Pedagógica. Foi constatado também que a maioria dos estudantes não tinha interesse pelas aulas de Filosofia, mas participaram e melhoraram o desempenho na disciplina, revelando que as aulas diferentes das tradicionais, com aplicação de alternativas metodológicas para ensinar a filosofar e formas diferenciadas de estimular a produção do conhecimento filosófico pelos estudantes do Ensino Médio a partir das artes, foram bem sucedidas. A partir dos temas proposto, os estudantes foram criativos e apresentaram várias possibilidades de contato com os saberes filosóficos de forma lúdica e a partir das suas próprias interpretações e potenciais.

Conforme os residentes, a proposta foi levar para a escola uma filosofia viva, criativa, produtiva, participativa, que saísse das aulas tradicionais e fizesse com que os estudantes tivessem uma experiência diferente com o pensamento filosófico. Consideramos que os objetivos foram atingidos, tanto no que tange à formação de professores, quanto nos resultados alcançados com os estudantes do Ensino Médio.

\section{AGRADECIMENTO}

Agradecemos à Preceptora Professora Luiza Paixão de Sousa Ferreira e toda a equipe gestora da Escola Estadual Santa Fé pela receptividade e apoio nas atividades e pela disposição em participar do programa, acreditando nessa parceria entre a escola e a universidade.

Todos os autores declararam não haver qualquer potencial conflito de interesses referente a este artigo.

\section{REFERÊNCIAS BIBLIOGRÁFICAS}

BERGMANN, J.; SAMS, A. Sala de aula invertida: uma metodologia ativa de aprendizagem. (Trad. Afonso Celso da Cunha Serra). $1^{\mathrm{a}}$ ed. Rio de Janeiro: LTC, 2016.

BRASIL. Parâmetros Curriculares Nacionais: PCNs Ensino Médio. Ministério da Educação, Secretaria de Educação Média e Tecnológica. Brasília: MEC, 1999.

COTRIM, G.; FERNANDES, M. Fundamentos de Filosofia. 2. ed. São Paulo: Saraiva, 2013.

FREIRE, Paulo. Pedagogia do oprimido. $17^{\mathrm{a}}$ edição. Rio de Janeiro: Paz e terra, 1987.

MURCHO, D. Ensino de Filosofia e avaliação. In.: GUIDO, H; ALMEIDA JR, J. B.; CANELON, M. (Orgs.). O transversal e o conceitual no Ensino de Filosofia. Uberlândia/MG: EDUFU, 2014. 